Türkiye Jeoloji Bülteni
Geological Bulletin of Turkey
$64(2021) 223-232$
doi: $10.25288 / t j .766968$

\title{
Porosity Prediction for Some Geological intervals in the East Baghdad Oil Field Using New Empirical Equations
}

\author{
Maan Hasan Abdullah Al-Majid (1D
}

University of Mosul, College of Petroleum and Mining Engineering, Mosul-Iraq

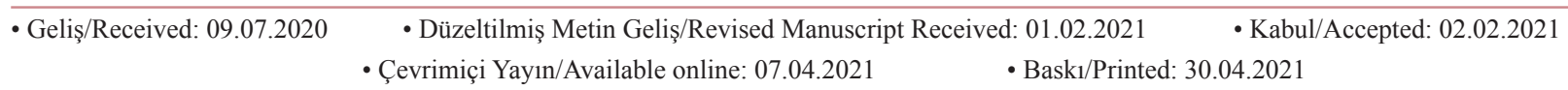
Research Article/Araştırma Makalesi Türkiye Jeol. Bül. / Geol. Bull. Turkey

\begin{abstract}
This study examines the evaluation of empirical equations related to primary seismic velocity with density and porosity. The empirical equations have been used in 128 sites based on a seismic grid covering the east Baghdad oil field. The average of density of the geological formations between each seismic reflectors and another (each interval) was extracted from well log data for four wells scattered in the field. Those reflectors were arranged from top to bottom of the studied Formations (Fatha, Hartha, Tanuma, Ahmadi, Shuaiba, and Gutnia Formations). In order to determine the best empirical equations, several previous equations were tested to obtain the best that correspond to the density rates taken from well records. The most suitable equations were used in calculating density for all intervals in the whole field. Using the strong relationship (porosity-density) taken from the well log data, the porosity values for all the studied intervals were found. Later, the porosity and density contour maps for each interval in the whole field were established. The locations of high porosity zones were identified and related to the petroleum distribution in the field.
\end{abstract}

Keywords: Density, East Baghdad oil field, petrophysical parameters, porosity, new empirical equations, seismic velocity analyses.

\section{INTRODUCTION}

The oil field of East Baghdad is one of Iraq's largest oil fields. It is about $120 \mathrm{~km}$ long and about 20-30 $\mathrm{km}$ wide and occupies an area of around $1000 \mathrm{~km}^{2}$ and is directed towards NW-SE (Figure1). The structure was highly faulted due to the transverse motion of the basement blocks, which led to the formation of the early Cenomanian longitudinal wrench faults. Many of these faults resemble positive flower structures on seismic sections (Harding and Lowell, 1979).

The oil field in eastern Baghdad was established in 1976 as a group of oil fields, the first oil field production in 1980. In this field many oil wells have been drilled which reach the Cretaceous formations, one of which penetrates all of the Cretaceous formations and extends to Chiagara Formation in the Upper Jurassic. Ratawi and Zubair Formations are regarded as the main source rocks for accumulation of hydrocarbons which constitute a petroleum system. (Darweesh, et al, 2017).

As indicated by C.F.P. (1981) and Khaiwka (1989), the structural complexity of east Bagdad oil field was resulted from oblique-slip growth faults and later folding and faulting.

\footnotetext{
* Correspondence / Yazıșma: maanabdalla@yahoo.com
}

(C) 2021 JMO Her hakkl saklıdır/All rights reserved http://tjb.jmo.org.tr http://dergipark.gov.tr/tjb 


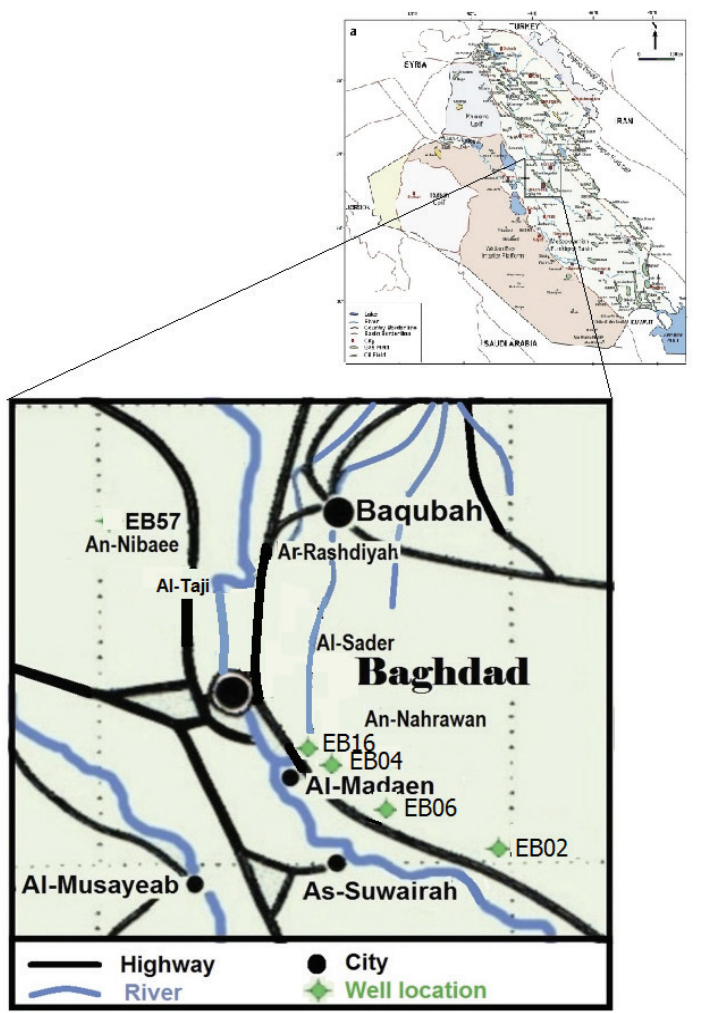

Figure 1. Location map of the study area. (Al-Ameri et al, 2016).

There are two main faults in the seismic section (Figure 2), the first is normal with NE dipping and cutting the tops of Ahmadi, Shuaiba, Chiagara and Gotnia Formations, while the second fault is normal, it is semi-vertical and it cuts the tops of the same formations as those mentioned above. Such faults make a good way to allow oil migration along the permeable calcareous sand and shale beds in Chiagara Formation in the horizontal movement to a route through faults in vertical movement and finally to the traps of the anticline.

From the crest to the spill plane, the termination of these traps is filled; where oil spills under the trap into permeable beds nearby. The spilled oil migrates through friction joints until it is trapped in the seal of Lower Fars Anhydrite (AlAmeri, 2011).

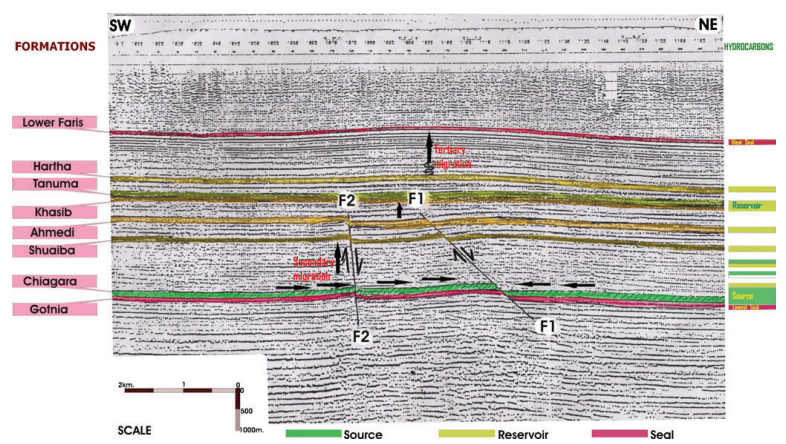

Figure 2. Seismic cross section played with hydrocarbon source, reservoir, and seal rock units in East Baghdad Oil Field. Double lines arrow indicate directions of migration pathways while F1 and F2 are normal faults (Al-Ameri, 2011).

The stratigraphic section includes several types of rock deposited in the marine and lagoon zones. The deposits range from Jurassic, Cretaceous and Pliocene in geological period (AlAmeri, 2011) (Figure 3).

\section{MATERIALS AND METHODS}

The density of the rock depends on the mineral content, porosity, water saturation and the hydrocarbon type. It will provide critical details to identify the reservoir or to schedule the location of the new well generated or injected.

Cross-plots of rock properties and pore fluid and lithology show that density makes the biggest distinction of hydrocarbon reservoirs and other types of rock fluid, making exact density estimates significant for characterization of the reservoir (Van Koughnet et al., 2003).

Conventional petrophysical investigations are focused on a P-wave seismic velocity analysis for predicting density information. The propagation of acoustic waves on porous material depends on the studied formation's lithology and porosity. There are a number of empirical equations which describe the P-wave velocity as a density and porosity function (Brocher, 2005). 


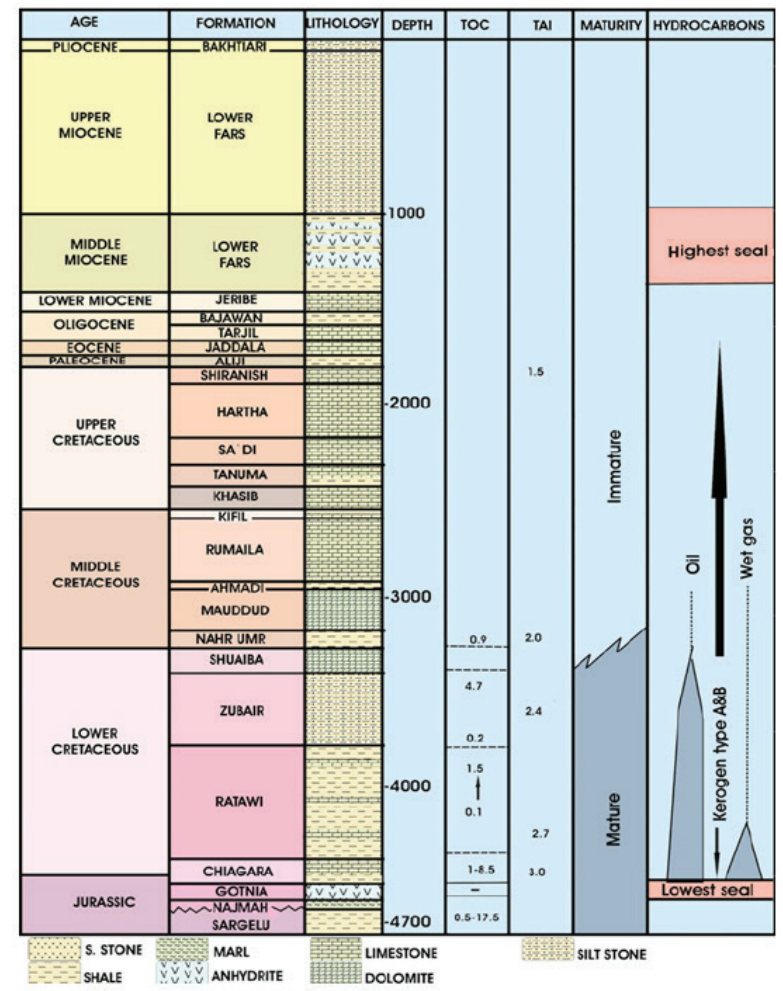

Figure 3. East Baghdad Oil field stratigraphy with parameters of hydrocarbon production and sealing within the total petroleum system. (Al-Ameri, 2011).

For the determination of sonic log data and the precise detection of pore fluids, velocity-porosity relationships are important. In order to interpret the sonic log data, it is important to assess the relationships between velocity in the sediments and rock lithology. The knowledge of accurate ties between velocity and other petrophysical parameters, such as porosity or density, are crucial for the measurement of impedance models (Han and Batzle, 2004).

If density and porosity details are not available, it is often calculated from $\mathrm{P}$-wave velocity (VP) by various relationships (Gardner et al, 1974; Lindseth, 1979; Barnola and White, 2001; and else.).

\section{Data Sources}

The data collected in this work were obtained from two primary sources. The first was based on a seismic data set taken from (Al-Majid, 1992) to derive information about the reflectors (depths and velocities). These data were used with different empirical equations to generate the porosity and density values for intervals (Fatha-Hartha, HarthaTanuma, Tanuma-Ahmadi, Ahmadi-Shuaiba, and Shuaiba-Gutnia). The seismic data comprised 128 sites scattered over a net of 22 seismic lines (Fig. $4)$.

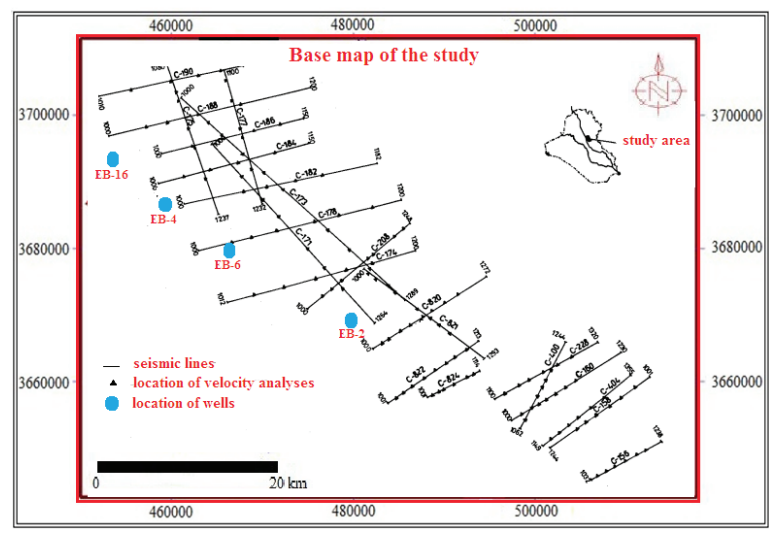

Figure 4. Location map of the seismic lines in the study area (modified after Al-Majed, 1992).

The second source was collected from log data of four wells dispersed in the field to measure the mean density and porosity values at various depths (reflector depths). The density rates taken from the well information were compared with the density values calculated using the previous empirical equations. Well log data were collected from the Iraqi Ministry of Oil for the four wells (EB2, EB4, EB6, and EB16). Such data provide details on the reservoir's petrophysical properties. The analysis of well log data requires the removal of any external factors, such as the mud cake and the effect of the drilling mud or other, that cause errors on reading logs. 
Corrections must be made for shaliness to determine porosity values with greater precision. After estimating shale volume from Gamma ray, the neutron-density measurements are adjusted for the shale effect. The log readings in this research have been corrected by using the interactive petrophysics software (IP) to make environmental corrections.

\section{Previous Empirical Equations}

Based on field and laboratory observations of salt-sated rocks, except evaporates, from different sites and depths, Gardner et al. (1974) found the empirical equations between density and velocity, given by:

$\rho=a(V)^{m}$

Where $\rho$ is density and V is P-wave velocity. Standard values of (a) and ( $\mathrm{m}$ ) in densities of $\mathrm{g}$ $/ \mathrm{cm}^{3}$ and $\mathrm{P}$-wave velocity in $\mathrm{m} / \mathrm{s}$ are 0.31 and 0.25 , respectively. The relationship of Gardner is a good approximation for shales, sandstones and carbonates, while coals and evaporates vary greatly from the predicted behavior. (Gardner, et al, 1974).

(Han et al., 1986) carried out detailed analyses on 75 sandstone cores of various porosity and clay content. The samples used are saturated with a pressure of $40 \mathrm{MPa}$. The equation (Eq.) derived from this dataset is:

$\rho=0.019$ VP .58

For a set of 13 limestone cores, (Kuiper et al., 1959) used the following equation:

$\rho=0.026 \mathrm{Vp}^{54}$

The associations between velocity and density are high for limestone data, but they are dispersed for sandstone data. Subsequently, Gardner et al.
(1974) correlated the variability of bulk density with P-wave velocities for specific sedimentary rocks from a wide range of ages, basins, and depths. The relationship of Gardner et al. (1974) is:

$\rho=0.31(\mathrm{VP})^{0.25}$

Whereas the default coefficients (a) and (b) in the original Gardner equation are 0.31 and 0.25 , respectively. (Nwozor, et al, 2017) applied the Gardner curve to its local results, leading in a coefficient of 0.33 and 0.29 for shales and sands, respectively, when the exponent is held at the default value.

$\rho=0.29(\mathrm{VP})^{0.25}$ (for Shale)

$\rho=0.33(\mathrm{VP})^{0.25}$ (for Sand)

\section{RESULTS}

Interval velocity (IV) results for all intervals Fatha-Hartha, Hartha-Tanuma, Tanuma-A1Ahmadi, Ahmadi-Shuaiba and Shuaiba-Gutnia were obtained from (Al-Majid, 1992). In order to determine the suitability of the empirical equations mentioned above in the calculation of the density values, these equations were tested to obtain the best that will be used to calculate the density on the whole field. This test was carried out on the well log information of the five wells distributed in the field. The average density values for all intervals produced from log data were compared with the others calculated by applying the empirical equations mentioned above (Table 1).

From Table 1, the average density values calculated by Eq.2 have roughly consistent with the well log data for the two intervals (TannumaAhmadi and Ahmadi-Shuaiba), but the others have none except those for Shuaiba-Gutnia interval that calculated by Eq. 5 
Table 1. Comparison between the average density values (Avg $\rho$ ) observed in the well logs data for five intervals and the others calculated by different empirical equations.

\begin{tabular}{|c|c|c|c|c|c|c|c|c|}
\hline Interval & $\begin{array}{c}\text { Top } \\
\text { Depth } \\
\text { m }\end{array}$ & $\begin{array}{l}\text { Bottom } \\
\text { Depth m }\end{array}$ & $\begin{array}{l}\text { Avg } \rho \text { Well } \\
\log \text { gm/cc }\end{array}$ & $\begin{array}{l}\text { Avg } \rho \\
\text { Eq.2 } \\
\text { gm/cc }\end{array}$ & $\begin{array}{c}\text { Avg } \rho \\
\text { Eq.3 gm/ } \\
\text { cc }\end{array}$ & $\begin{array}{c}\text { Avg } \rho \\
\text { Eq.4 gm/ } \\
\text { cc }\end{array}$ & $\begin{array}{c}\text { Avg } \rho \\
\text { Eq.5 gm/ } \\
\text { cc }\end{array}$ & $\begin{array}{c}\text { Avg } \rho \\
\text { Eq.6 gm/ } \\
\text { cc }\end{array}$ \\
\hline Fatha- Hartha & 1200 & 1650 & 2.4811 & 2.2271 & 2.1941 & 2.4161 & 2.2602 & 2.5665 \\
\hline Hartha-Tannuma & 1600 & 2020 & 2.4141 & 2.3548 & 2.3110 & 2.4748 & 2.3151 & 2.6345 \\
\hline Tannuma-Ahmadi & 2000 & 2950 & 2.4251 & 2.4133 & 2.3644 & 2.5011 & 2.3400 & 2.6625 \\
\hline Ahmadi-Shuaiba & 2950 & 3260 & 2.499 & 2.4881 & 2.4325 & 2.5338 & 2.3703 & 2.6972 \\
\hline Shuaiba-Gutnia & 3260 & 3820 & 2.3605 & 2.4584 & 2.4055 & 2.5212 & 2.3585 & 2.6838 \\
\hline
\end{tabular}

According to the equations concluded by (Nworoz, et al 2017) using two values of parameter a $(0.29$, and 0.33$)$, five new equations for the five intervals in the study area were created with variable values of a range from 0.29 to 0.32 and constant $b$ parameter $(0.25)$.

$\rho=a(V P)^{0.25}$

These equations were established for the purpose of obtaining the best match in density values calculated from velocity data and those produced by well log information (Table 2 ).
The parameter (a) was explained as a variable lithological parameter ranging from 0.29 in Shuaiba-Gutnia interval (containing the low density Shale) to 0.32 in Fatha-Harth interval (containing the high density anhydrite).

The new five equations were used to estimate the density values for each interval in the whole field. Later, five density maps for the five intervals were produced. (Figure 5).

Table 2. Comparison between the average density values observed in the well logs data for all intervals and the others produced by the new empirical equations with variable parameters of (a) and constant (b) (according to this study).

\begin{tabular}{cccccccc}
\hline Interval & $\begin{array}{c}\text { Top } \\
\text { depth } \\
\text { in m }\end{array}$ & $\begin{array}{c}\text { Bottom } \\
\text { depth } \\
\text { in } \mathbf{~ m}\end{array}$ & $\begin{array}{c}\text { Avg } \boldsymbol{\rho} \text { well } \\
\mathbf{l o g} \\
\text { in } \mathbf{~ g m / c c ~}\end{array}$ & $\begin{array}{c}\text { Avg } \boldsymbol{\rho} \\
\text { New Eq.(8) } \\
\text { in } \mathbf{~ g m / c c ~}\end{array}$ & (a) & (b) & Error \\
\hline Fatha- Hartha & 1200 & 1650 & 2.4811 & 2.48096935 & 0.32 & 0.25 & -0.00013 \\
Hartha-Tannuma & 1650 & 2000 & 2.4141 & 2.418924857 & 0.303 & 0.25 & 0.00482 \\
Tannuma-Ahmadi & 2000 & 2950 & 2.4251 & 2.420440637 & 0.30 & 0.25 & -0.00465 \\
Ahmadi-Shuaiba & 2950 & 3260 & 2.499 & 2.501071976 & 0.306 & 0.25 & 0.00207 \\
Shuaiba-Gutnia & 3260 & 3820 & 2.3605 & 2.358514119 & 0.29 & 0.25 & -0.00198 \\
\hline
\end{tabular}



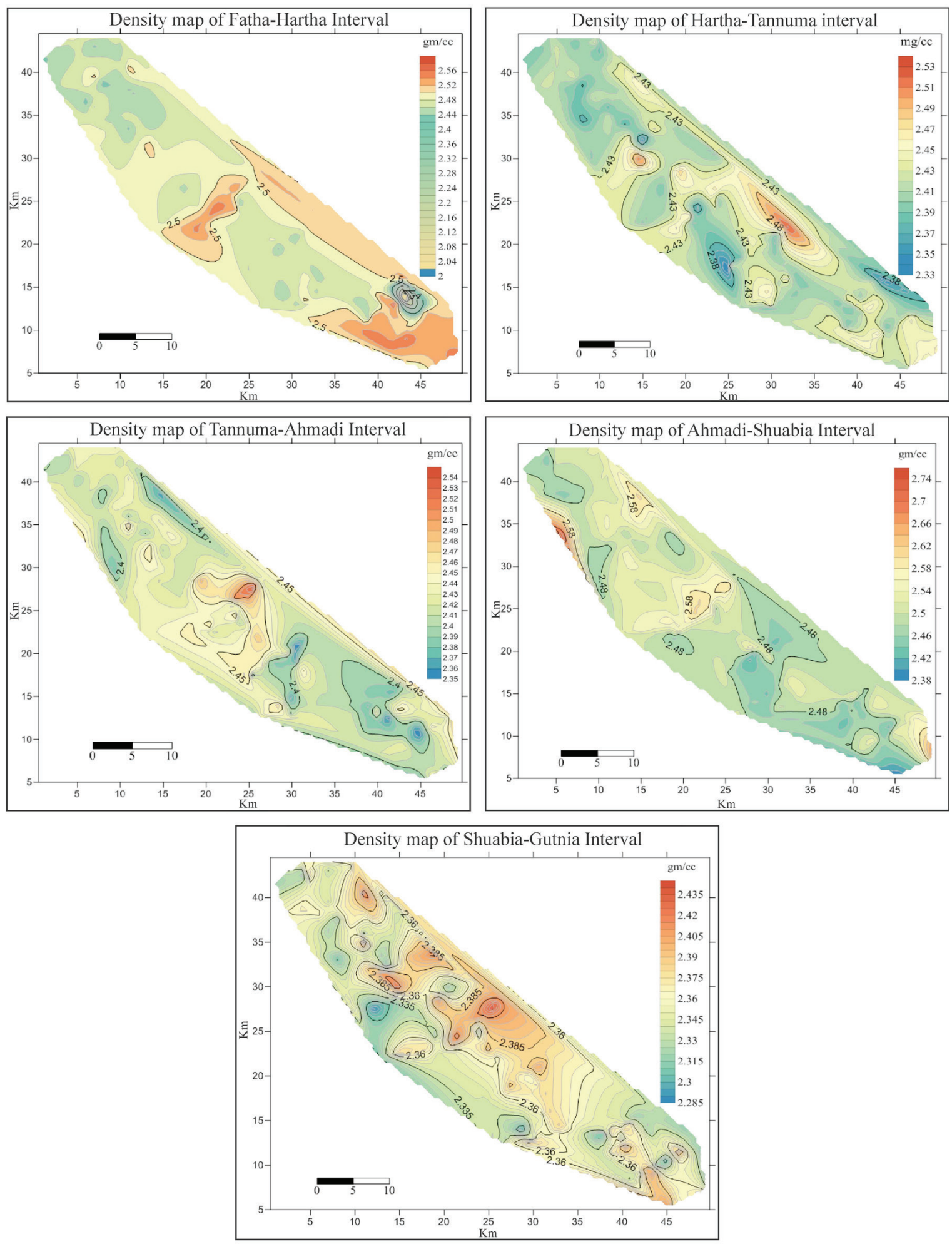

Figure 5. The density maps for each interval in the study area produced by using Surfer program v.13. 
For porosity values in the field, porosity and density data from five well logs in the field were used to establish a new empirical relationship between them with high correlation coefficient $(\mathrm{R}=0.9)$ (Figure 6).

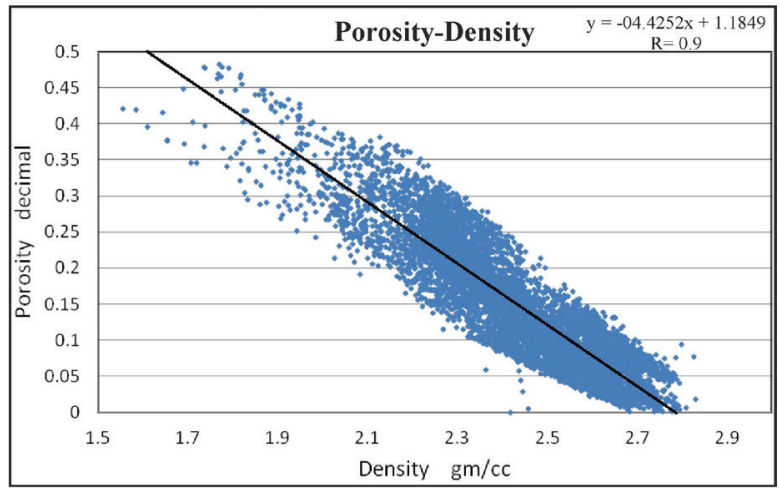

Figure 6. A relationship between porosity and density values recorded in the well logs and its parameters.

For more accuracy, the best porosity - density equations for each interval were deduced as shown in Table 3.

Table 3. The best Porosity - density equations for all intervals in the study area, where $\Phi$ is the porosity in decimal, $\rho$ is the density in $\mathrm{gm} / \mathrm{cc}$, and $\mathrm{R}$ is the correlation coefficient between.

\begin{tabular}{ccc}
\hline Interval & $\begin{array}{c}\text { Porosity-Density Best } \\
\text { equation }\end{array}$ & $\mathrm{R}$ \\
\hline Fatha-Hartha & $\Phi=-0.5304 \rho+1.434$ & 0.91 \\
Hartha-Tannuma & $\Phi=-0.6596 \rho+1.7619$ & 0.996 \\
Tannuma-Ahmadi & $\Phi=-0.5079 \rho+1.3895$ & 0.94 \\
Ahmadi-Shuaiba & $\Phi=-0.3195 \rho+0.9028$ & 0.79 \\
Shuaiba-Gutnia & $\Phi=-0.364 \rho+1.0495$ & 0.87 \\
\hline
\end{tabular}

These equations were used to calculate the porosity values for each interval in the whole field. Later, five porosity maps for the five intervals in the whole field were derived (Figure7).

\section{DISCUSSION AND CONCLUSIONS}

After conducting the necessary tests on previous equations to obtain the best relationship between seismic velocity and density, the best equation for each interval was established. According to lithilogical section in each interval, the variable (a) in the equations was ranging between 0.29 and 0.32. It appears as an index factor to knowledge of rock types in the study sections. This study concludes a new (a) value for each interval by best fit the calculated average densities with those produced from well log.

The Fatha-Hartha interval which has variable and successive lithological cycles (Limestone, Dolomite, Anhydrite, Marl, Claystone, and Salt rocks) with an average density of about 2.48, showed the highest value of the factor (a), which is about (0.32).

The Hartha - Tanuma interval which is the main component of Limestone with average density of about (2.41) gm/cc has a value of (a) about 0.303 , that may be considered as a characteristic value of limestone in the field.

The Tannuma-Ahmadi interval has a value of (a) about (0.30) for sequences of limestone layers with thin overlays of Shale. The average density calculated of this interval is about (2.425). The Shale effect reduces the value of (a) from 0.303(for only Limestone layer) to 0.30 (for thickly Limestone with thin layers of Shale). This may be mean that the shale effect on (a) value in this interval is about (0.003).

In the Ahmadi-Shuaiba interval which consists of thick Dolomite layers with some layers of Shale, the (a) value was increased to about (0.306). Although the Shale layers in this interval have a more thickness than Tannuma-Ahmadi interval, the values of (a) were increased. This may have occurred due to the replacement of dolomite instead of limestone, which may give an idea of the effect of dolomite on increasing the value of (a). The Shuaiba - Ahmadi interval consists mainly of Shale which reduces the value of (a) to (0.29). The (a) value in this interval was corresponded to the value derived by (Nwozor, et al, 2017) from their study for a number of Shale samples. 

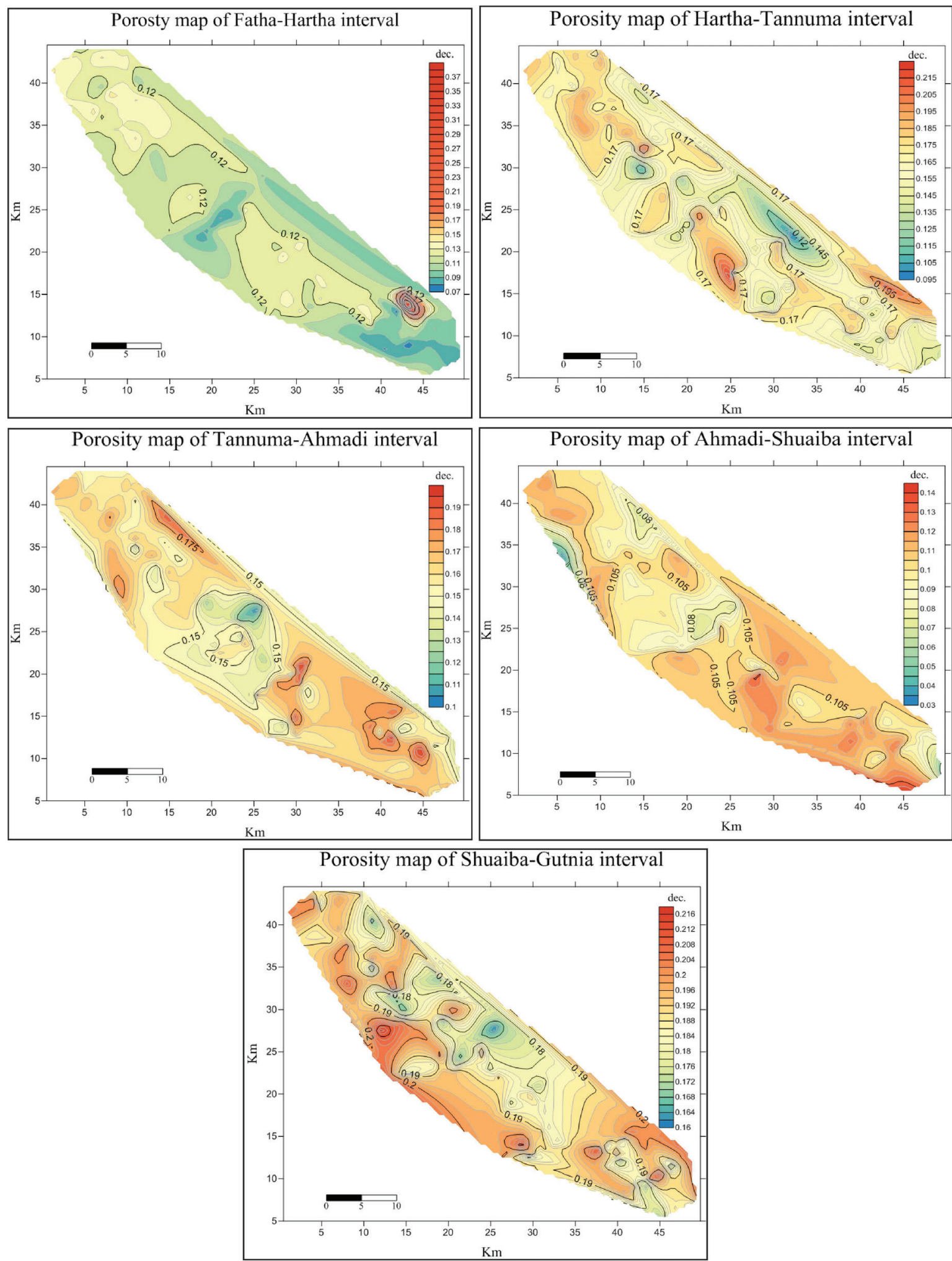

Figure 7. The porosity maps of each interval in the study area produced by using Surfer program v.13 
Based on wells information, the new relationships between porosity and density were obtained for each interval with a high correlation coefficient (R) ranges from 0.78 to 0.99 . The equations deduced from these relationships were applied to density values calculated above for the purpose of obtaining porosity values for each interval.

Density and porosity maps were plotted for each period. The high porosity areas were determined to provide important evidence on the sites of hydrocarbons in the study area.

The presence of Shale in the Stratigraphic section is considered the greatest effect on the increase of porosity in the study area, but this effect decreases with increasing depth due to the effect of overburden pressure except in the last interval (Shuaiba-Gutnia), where porosity increases despite the increase in depth. This may occurs when the pore pressure is effective. This assumption may give a clear picture of the distribution of hydrocarbons in that interval.

\section{ORCID}

Maan Hasan Abdullah Al-Majid D https://orcid.org/0000-0002-3951-4880

\section{REFERENCES}

Al-Ameri, T.K. (2011). Khasib and Tannuma oil sources, East Baghdad oil field, Iraq. Marine and Petroleum Geology, 28(4), 880-894. https://doi. org/10.1016/j.marpetgeo.2010.06.003

Al-Ameri, T. K., Al-Temimi A. K. \& Zumberge J. (2016). Assessments of oil characterization, source affinities, and hydrocarbon dynamic of East Baghdad oil fields, Central Iraq. Marine and Petroleum Geology, 77, 353-375. https://doi. org/10.1016/j.marpetgeo.2016.03.009

Al-majid, M. (1992). The study of compaction in the east Baghdad oil field by using seismic velocity analyses (Unpublished MSc thesis). University of Mosul, Iraq.
Barnola, A. S. \& White, R. E. (2001). Gardner's relation and AVO inversion. First Break, 19(11), 607-611.

Brocher, T. M. (2005). Empirical relations between elastic wave speeds and density in the Earth's crust. Bulletin of the Seismological Society of America, 95(6), 2081-2092.

C.F.P. (Compagnie FranGaise du Pdtrole) (1981). East Baghdad field: sedimentological study of the carbonate reservoirs. Oil Exploration Co, Baghdad [Unpublished report].

Darweesh, H. A., Obed, A. M. \& Albadran, B. N. (2017). Structural study of East- Baghdad oil field, Central-Iraq. World Journal of Engineering Research and Technology, 3(6), 56 -66.

Gardner, G. H. F., Gardner, L. W. \& Gregory, A. R. (1974). Formation velocity and density the diagnostic basics for stratigraphic traps. Geophysics, 39, 770-780.

Han, D. H., Nur, A. \& Morgan, D. (1986). Effects of porosity and clay content on wave velocities in sandstones. Geophysics, 51, 2093-2107.

Han, D. H. \& Batzle, M. (2004). Gassmann's equation and fluid-saturation effects on seismic velocities. Geophysics, 69, 398-405.

Harding, T. P. \& Lowell, J. D. (1979). Structural styles, their plate-tectonic habitats, and hydrocarbon traps in petroleum province. The American Association of Petroleum Geologists Bulletin, 63(7),10161058 .

Khaiwka, M. H. (1989). Structural evolution of the East Baghdad oilfield, central Iraq. Proc. 5th Sci. Con., Scientific Research Council, Baghdad, 2,(1), 17-27.

Kuiper, J., Van Ryan, W. M. L. \& Kocfoed, O. (1959). Laboratory determinations of elastic properties of some limestones. Geophysical Prospecting, 7(1), 38-14.

Lindseth, R. O. (1979). Synthetic sonic logs - a process for stratigraphic interpretation. Geophysics, 44, $3-26$. 
Nwozor, K. K., Onuorah, L. O., Onyekuru, S.O. \& Egbuachor, C. J. (2017). Calibration of Gardner coefficient for density-velocity relationships of tertiary sediments in Niger Delta Basin. Journal of Petroleum Exploration and Production Technology, 7, 627-635. https://doi.org/10.1007/ s13202-017-0313-7
Van Koughnet, R. W., Skidmore, C. M., Kelly, M. C. \& Lindsay, R. (2003). Prospecting with the density cube. The Leading Edge, 22, 1038-1045. 